\title{
DIE SLEUTEL VAN JERUSALEM
}

Mnr JA Visser*

The article below, dealing with the role of the South African Artillery in the capture of Nebi Samwil (8 km northwest of Jerusalem) during World War 2, is but a short extract from a much more comprehensive work on the SA artillery that is being undertaken by the Military Information Bureau, Pretoria.

One of the burning questions that still remains unanswered is: what happened to the historic canon, on which the Key of Jerusalem was engraved, that played such a vital part in this particular campaign?

If anyone should have information on the whereabouts of these canon, he is requested to contact the Military Information Bureau at Private Bag X 289, Pretoria 0001 (telephone no 28-1731 $X$ 554), as soon as possible.

\section{Inleiding}

Nebi Samwil (ook Samweil of Neby Samwal gespel) is 'n hoogte van tussen $400-500$ vt ongeveer $8 \mathrm{~km}$ noordwes van Jerusalem en wat bekend staan as die Sleutel van Jerusalem. Hierdie hoogte, geleë op 'n plato, is vanweë sy strategiese posisie in die verlede nog altyd beskou as die sleutel tot enige offensief wat teen die Heilige Stad gerig is. Nebi Samwil is in die Ou Testament bekend as Mispa. Volgens oorlewering is dit ook die plek waar Richard die Leeuhart sy gesig verberg en geweier het om na Jerusalem te kyk omdat hy die stad nie kon verower nie. Verder word die hoogte deur Christene, Jode en Mohammedane aanvaar as die plek waar die profeet Samuel begrawe is. Oor sy vermeende graf is ' $n$ wit moskee met ' $n$ lang minaret gebou.

\section{Eerste Wêreldoorlog}

In Julie en Augustus 1915 is in die Unie van Suid-Afrika ' $n$ aanvang gemaak met rekrutering vir die "Imperial Service Contingent Unit". Na die veldtog in Oos-Afrika het die South African Field Artillery (SAFA) in April 1917 teruggekeer na die Unie en is die eenheid gereorganiseer en op sterkte gebring vir diens in Noord-Afrika. Hierdie eenheid het uit vrywilligers bestaan. Die SAFA is nou weer saamgestel en lede is uit die Cape Field Artillery (CFA), die Natal Field Artillery (NFA) en die Transvaal Horse Artillery (THA), getrek. Daar is ooreengekom dat die brigade by 75 Divisie, wat bestem was vir diens in Palestina, ingedeel word. Die brigade het bestaan uit $A$ en $B$ Batterye wat elk met $6 \times 18$-pondergeskut toegerus is. C Battery was 'n addisionele battery met $4 \times 4,5 \mathrm{dm}$ houwitsers en die brig- ade is as veldartillerie en nie soos voorheen berede artillerie nie, georganiseer. Hierdie Battery sou ook bekend staan as die Houwitsers en het eers op 11 April 1918 tot die stryd in Palestina toegetree.

Die 75 Divisie het op die hoofroete vanaf Jaffa na Jerusalem opgeruk. Binne $8 \mathrm{~km}$ van die Heilige Stad, noord van die aanmarsroete, was die Turkse magte op hoë grond ontplooi. Opdrag is aan 75 Divisie gegee om die roete noord van Jerusalem af te sny. Tydens die opmars loop hulle hul in die Turkse stellings vas en dit is hier waar die SAFA met onderskeiding opgetree het.

In 'n pas naby Kustil (ook Kustul gespel) het die infanterie, ondersteun deur B Battery, daarin geslaag om die Turke te verdryf en beide $A$ en $B$ Batterye bo-op die pas te konsolideer. In die nag van 20 November 1917 het die infanterie in reën, sonder dat hulle daarvan bewus was, binne sig en trefafstand van die vyand gekampeer. Toe dit die volgende oggend lig word was hulle ' $n$ oop teiken vir die vyand en hulle is ook dadelik met barstende bomme begroet. Bevel is aan die SAFA Brigade gegee om hulle kanonne aan te haak en vorentoe te beweeg. Die Turke was so besig om die infanterie te bombardeer dat hul nie opgemerk het dat A Battery in gereedheid kom om vuur op hulle af te bring nie. Op 'n afstand van ongeveer 3000 meter is die wêreld vir die Turke so warm gemaak dat hul verplig was om terug te val en skuiling te soek.

Met die aankoms van 75 Divisie by Biddu, vind hul dat die hoogte van Nebi Samwil in die hande van die Turke is en dat die roete na Bireh van- 


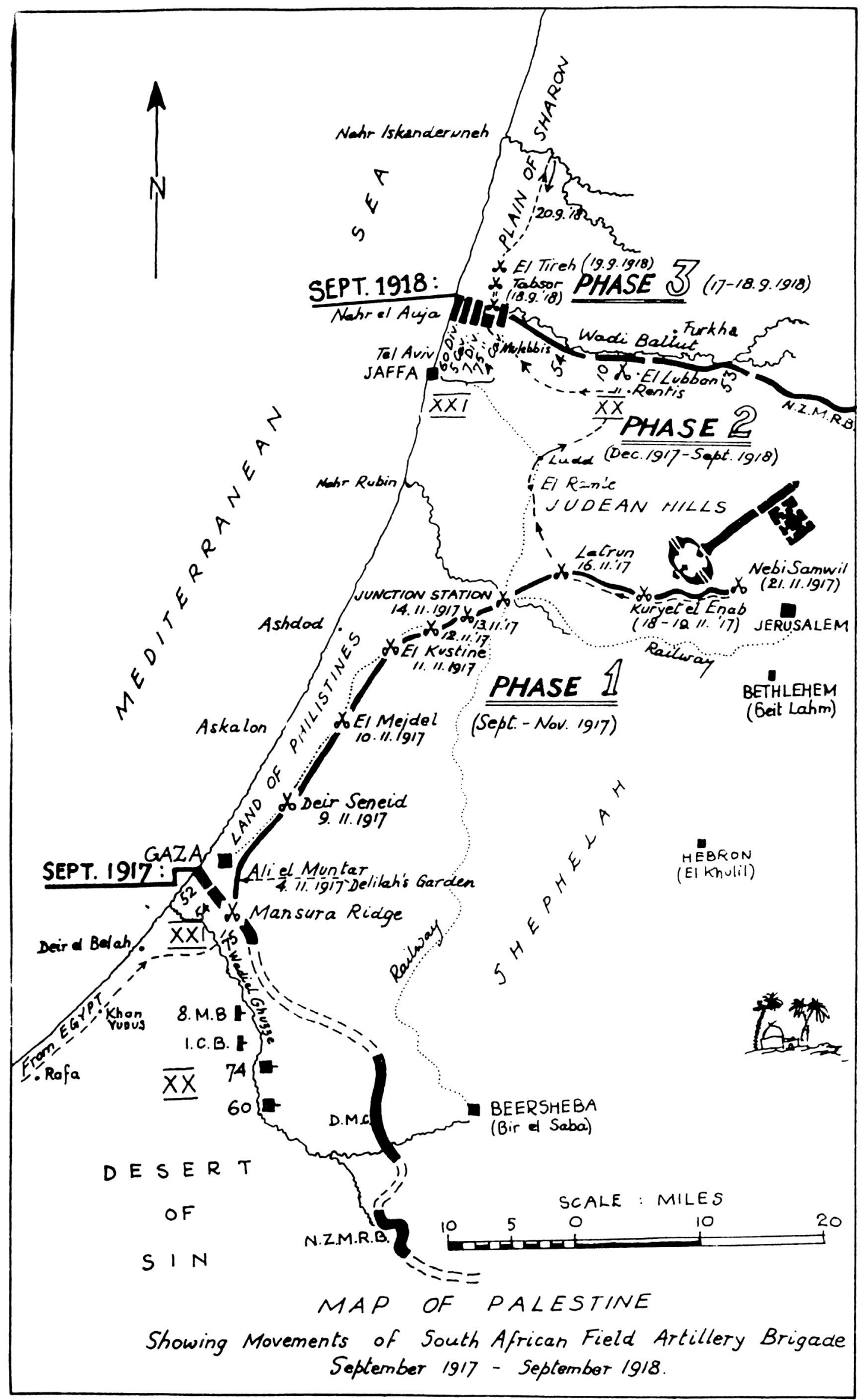


daar beheer word. Vanaf die hoogte van Nebi Samwil word ook die toegang tot Jerusalem beheer. Die 234ste Infanterie het dadelik tot die aanval oorgegaan en net voor middernag van 21 November die stelling verower. Die volgende dag, 22 November 1917, het die Turke nog drie mislukte aanslae teen die hoogte van stapel gestuur. Gedurende die verbete gevegte wat daar plaasgevind het, is die moskee oor die graf van Samuel in puin gelê.

Alhoewel 75 Divisie die weg tot die verowering van Jerusalem gebaan het, was dit hulle nie beskore om die stad self in besit te neem nie. Hulle moes by die stad verby trek om ander militêre opdragte uit te voer.

\section{Die sleutel van Jerusalem as kenteken}

Vir 75 Divisie se aandeel in die verowering van Nebi Samwil is aan hul ' $n$ kenteken in die vorm van ' $n$ sleutel toegeken omdat hulle die "Sleutel van Jerusalem" verower het. Hierdie kenteken is op die pantserplaat van hul kanonne asook op geskikte plekke op ander uitrusting aangebring.

\section{Die kenteken op Suid-Afrikaanse uitrusting}

$\mathrm{Na}$ afloop van die oorlog het die SAFA op 29 April 1919 by Suez aan boord gegaan en huiswaarts gekeer. A en B Batterye moes hul 18ponder-kanonne voor hul vertrek aan die Royal Artillery teruggee en het hulle oorspronklike 13ponders, waarmee hulle aanvanklik uitgerus was, terug ontvang. Ofskoon C Battery se 4,5 $\mathrm{dm}$ houwitsers, wat in Egipte aan hulle uitgereik was, eers na die slag van Nebi Samwil in Palestina ontplooi is, was dit egter die enigste geskut van die SAFA waarop die sleutel aangebring is wat na Suid-Afrika teruggebring is. Hierdie houwitsers is weer teen die vyand in Oos-Afrika gedurende die Tweede Wêreldoorlog gebruik.

Hierdie greep uit die artilleriegeskiedenis van Suid-Afrika vorm deel van 'n groter kroniek wat tans deur die Militêre Informasieburo (SAW) saamgestel word. Hierdie werk, wat heelwat navorsing in beslag geneem het, sal na verwagting in 1987 verskyn. Die samestellers ondervind egter probleme met leemtes in die geskiedenis en daar is nog talle onbeantwoorde vrae. Een tergende vraag is: wat het van hierdie historiese kanonne met die Sleutel van Jerusalem op hul gegraveer geword? Indien daar iemand is wat weet waar hierdie kanonne is, word hy dringend versoek om met die skrywer van hierdie artikel in verbinding te tree by Militêre Informasieburo, Privaatsak X289, Pretoria 0001 (tel 28-1731 X554).

${ }^{\star} \mathrm{Mnr}$ JA Visser, MA, TOD is verbonde aan die Militêre Informasieburo van die SAW.

\section{Bronnelys}

1. FB Adler ea: The SA Field Artillery in German East Africa and Palestine 1915-1919

2. AP Wavell: The Palestine Campaigns

3. MGE Bowman-Manifold: An Outline of the Egyptian and Palestine Campaigns, 1914-1918

4. C Falls ea: History of the Great War: Military operations Egypt \& Palestine from June 1917 to the end of the War - Part 1

5. The Royal Artillery War Commemoration Book 